\title{
Challenges of creative collaboration in geographical research
}

\author{
Candice P Boyd \\ The University of Melbourne, Australia
}

\section{Kaya Barry}

Griffith University, Australia

\begin{abstract}
There is a long history of collaboration between artists and geographers, with creative forms of research and dissemination of findings taking shape as artworks. In addition, there has been significant push from academia for researchers to maximise their research in ways that cater to, and engage with, broader public audiences. Art and creative practices tap into this through formats such as exhibitions, performances and participatory workshops which draw upon arts-based research methodologies with which geographers are becoming increasingly engaged. However, with this enthusiasm to adopt art practices for research dissemination purposes, tensions can arise in determining the levels of collaboration and authorship between artists and geographers, especially when the artist is employed as a research assistant on the project. In this 'In Practice' article, we explore the tensions and challenges that creative collaborations produce with respect to copyright and authorship, specialist skills and the delicate balance of doing creative research as part of a research team. We argue that geographers and artists need to address these issues from the outset and revisit them throughout the research process, and we offer some suggestions for how art-geography research collaborations might best be negotiated.
\end{abstract}

\section{Keywords}

art-geography, authorship, copyright, creative research, research collaboration

\section{Introduction}

Creative forms of research arising from the visual and performing arts encompass a range of outputs and forms such as physical works (sculpture, prints and drawn media), digital (video, film, audio, soundscapes and music) and performative works (theatre, improvised performance and 
performance art). Due to the range of media and forms that creative research entails, it now sits alongside, and complementary to, traditional forms of data collection and analysis in cultural geography. Creative collaboration between artists and geographers has a strong history and growing momentum ${ }^{1}$ under the titles of 'creative geographies', 2 "practice-led' 3 or practice-based' 4 geographical research, as well as 'artistic research' more broadly ${ }^{5}$ in the creative arts ${ }^{6}$ and social sciences. ${ }^{7}$ Work produced as 'creative geography' ${ }^{8}$ also aligns with disciplinary and institutional trends that encourage researchers to communicate their research findings in ways which make them more accessible to a broader public.

The concerns in this article, however, stem from our experiences as 'artist-geographers'. To varying degrees, across different projects and in our own research, we have produced creative work as inquiry, ${ }^{9}$ as knowledge translation ${ }^{10}$ and as part of larger, multi-disciplinary research efforts. ${ }^{11}$ We see our research as operating in a hybrid space that is based in scholarship yet also utilises our artistic skills. Not only do we understand the enthusiasm that researchers feel by incorporating a creative component into their research project, we feel it too. It feels good that after years of practice and experimentation in research-creation that our skills as researchers, who also practice creatively, have become highly sought after by others in our field. Nonetheless, and in our experience, issues of ownership and authorship have arisen over the course of our work whereby the processes involved in 'creative practice' have rubbed up against the notion of 'collaboration' - a somewhat grey and murky area when an artist, who is also a researcher, is hired to produce an artwork work as part of a research project. And so, in this short piece, we want to attend to some important distinctions between 'research collaboration' and 'creative production', as well as issues surrounding copyright and ownership.

\section{Copyright and ownership}

Although different countries and institutions have their own laws and arrangements, copyright is generally held by the creator of a work and not the person who paid for it:

For the purposes of copyright law, an 'author' is a person who creates the work, for example, writing an instruction manual, or drawing graphics, or writing a computer program. For photographs, the author is the person who takes the photograph. A person who contributes ideas or information or suggestions, but does not contribute to the expression of a work, is not considered to be an 'author' for the purposes of copyright. ${ }^{12}$

If, however, the artist is employed as a 'research assistant' on the project, rather than having a clear role as a member of the research team who is producing and co-authoring the research, then this can be slightly different, because '[g]enerally, a company owns copyright in copyright material created by an employee, provided the employee is not an independent contract or freelancer; and the work is created as part of that person's job' ${ }^{13}$ In this case, the work is owned not by the lead researcher who secured grant funding, nor the artist, but the institution under which the artist is employed.

And yet, this is even further complicated by the fact that many institutions have statutes specifically dealing with copyright that, in effect, 'pass it back' to the employee when the work is produced as academic inquiry, and so it is important to establish these conditions (in relation to funding source and the academic institution in question) before commencing work on a project. For instance, the University of Melbourne, where one of us works, stipulates that all scholarly material is owned by its academics. As such, the copyright associated with a creative work produced as part of a research project by an artistic researcher, who is identified as such, is likely owned by them exclusively. 


\section{Research collaboration versus creative production}

Issues of ownership regarding an artwork are legal. While this is important to the research-creation process, there are other factors surrounding collaboration that also come into play. In particular, we want to draw a distinction between research collaboration and the creative production of research. First, research collaboration is about the sharing of thoughts and ideas - for instance, a lead researcher can pay a research assistant to collect data but that is not regarded as 'collaboration' unless the research assistant engages with the material at an intellectual level (see Note 13). In a similar vein, while an artistic researcher may be included in the research collaboration because their thoughts and ideas are valued, we see that artists who are also researchers tend to be sought after for their creative skills, which may appear separate from their intellectual input.

In contrast, the creative process is about negotiating 'the relations between the various bodies that enable art to come into being' 14 including the insights that emerge in the dense 'space-times' of creative production. It is precisely this sense of 'doing' the creative work and the 'liquid knowing' that emerges from it that defines artistic inquiry. ${ }^{15}$ It is also in this sense that practice-led research brings value to the research process, not just as illustrative potential to translate academic research to audiences beyond scholars, but also in the processual and emergent aspects of experimenting with data and concepts (see Note 9). Therefore, our second point is that while research collaboration does not equate to creative co-production, creative production by artist-geographers does count as research. This does not mean that geographers who pay artistic researchers as research assistants cannot collaborate in the production of an artwork by way of contributing artistic skill. They can, but this needs to be carefully managed and clearly negotiated in a way that recognises and acknowledges how creative production differs from research collaboration, and that the 'artist-geographer' has a specific skill set that the 'commissioning' researcher may not have.

\section{Future directions for art-geography collaborations}

Creative work as geographical research is a rich and stimulating area that should be encouraged. However, challenges arise through uncertainties of 'who does what' as well as levels of attribution, ownership and authorship when artistic researchers are employed to assist on a research project. In this short piece, we have raised the importance of negotiating collaborative terms, production modes, copyright and authorship from the very beginning.

As Hawkins argues, there are challenges for creative geographers in terms of the potential 'underappreciation of creative skill' (see Note 1). It is not to separate or segregate the level of expertise or skill from those less exposed to creative practice, as she importantly points out, but rather to acknowledge that there are distinctions to be made in abilities and what creative work can bring to a research project. In addition, we acknowledge that artistic researchers may need to assert their rights more formally in situations where they are employed 'only' for their artistic skills, rather than a contributor to the research team. More importantly, we argue that recognising artistic work as scholarly output is a legacy from creative arts research that geographers need to adopt in all their creative collaborations.

\section{Acknowledgements}

As authors, we would like to assert an equal contribution to this article on behalf of us both.

\section{Funding}

The author(s) received no financial support for the research, authorship and/or publication of this article. 


\section{ORCID iD}

Candice P Boyd iD https://orcid.org/0000-0003-2796-8559

\section{Notes}

1. H.Hawkins, 'Geography's Creative (re)Turn: Toward a Critical Framework', Progress in Human Geography, 43, 2018, pp. 963-84.

2. S.A.Marston and S.De Leeuw, 'Creativity and Geography: Toward a Politicized Intervention', Geographical Review, 103(2), 2013, pp. iii-xxvi.

3. K.Barry and J.Keane, Creative Measures of the Anthropocene: Art, Mobilities, and Participatory Geographies (Singapore: Palgrave Macmillan, 2019).

4. C.P.Boyd, Non-representational Geographies of Therapeutic Art Making: Thinking Through Practice (London: Palgrave Macmillan, 2017).

5. C.P.Boyd and C.Edwardes (eds), Non-Representational Theory and the Creative Arts (Singapore: Palgrave Macmillan, 2019).

6. E.Barrett and B.Bolt (eds), Practice as Research: Approaches to Creative Arts Enquiry (London: I.B. Tauris, 2007).

7. L.Candy and E.Edmonds, 'Practice-Based Research in the Creative Arts: Foundations and Futures from the Front Line', Leonardo, 51(1), 2018, pp. 63-9.

8. P. Leavy, Method Meets Art: Arts-Based Research Practice. (New York: The Guilford Press, 2015).

9. K.Barry, 'Creative Arts Practice', in M.Büscher, M.Freudendal-Pedersen and S.Kesselring (eds), Handbook of Methods and Applications for Mobilities Research (Cheltenham: Edward-Elgar, in press).

10. K.Barry, 'The Aesthetics of Aircraft Safety Cards: Spatial Negotiations and Affective Mobilities in Diagrammatic Instructions', Mobilities, 12(3), 2017, pp. 365-85.

11. C.P.Boyd and R.Hughes, Emotion and the Contemporary Museum: Development of a GeographicallyInformed Method of Visitor Evaluation (Singapore: Palgrave Macmillan, 2020).

12. Australian Copyright Council: Information Sheet, $<$ https://www.copyright.org.au/acc_prod/ACC/ Information_Sheets/An_Introduction_to_Copyright_in_Australia.aspx $>$

13. ICMJE: Recommendations, <http://www.icmje.org/recommendations/browse/roles-and-responsibilities/defining-the-role-of-authors-and-contributors.html $>$

14. B.Bolt, 'Introduction: Toward a "New Materialism" for the Arts', in E.Barrett and B.Bolt (eds), Carnal Knowledge: Towards a 'New Materialism' Through the Arts (London; New York: I.B. Tauris, 2013), pp. 1-14.

15. R.Nelson, Practice as Research in the Arts: Principles, Protocols, Pedagogies, Resistances (London: Palgrave Macmillan, 2013).

\section{Author biographies}

Candice P Boyd is Australian Research Council DECRA Fellow in the School of Geography, University of Melbourne. Her interests include creative arts research, affective knowledge translation, cultures of sense and movement, and experiences of rurality.

Kaya Barry is a Postdoctoral Research Fellow working in the areas of mobilities, cultural geography, tourism, material cultures and creative arts research. Her recent projects have resulted in numerous exhibitions and publications that draw on site-specific ethnographic engagements with tourists, migrants, and local communities in Australia and Europe. 